[Agr. Biol. Chem., Vol. 33, No. 12, p. 1682 1690, 1969]

\title{
Studies on Sulfur-containing Carbonates and Their Pesticidal Activities
}

\author{
Part I. Relation of Chemical Structure to Acaricidal Activity \\ in S Substituted Benzyl O Substituted-Benzyl Dithiocarbonates
}

\author{
By Shigeki Wakamori, Takeo Tsuchidate and Yoshio Ishi \\ Research Laboratory, Tia Agricultural Chemical Co., Ltd., \\ Odawara, Kanagawa-Pref.*
}

Received December 20, 1968

\begin{abstract}
Several S-substituted-benzyl O-substituted-benzyl dithiocarbonates were synthesized and their acaricidal activities with Tetranychus urticae Koch were examined. Some dithiocarbonates, such as S-benzyl O-4-chlorobenzyl dithiocarbonate, S-benzyl O-4-bromobenzyl dithiocarbonate, S-benzyl O-3-methoxylbenzyl dithiocarbonate, S-3-methylbenzyl O-4-chlorobenzyl dithiocarbonate and S-3-methoxybenzyl O-4-chlorobenzyl dithiocarbonate, showed high ovicidal activities.
\end{abstract}

Various xanthates have been widely used as oil lubricators and accelerators of rubber vulcanization. Concerning biological activities of xanthate derivatives, activities of the xanthogen disulfides with lice, chiggers and ticks were reported by S. V. Zhuravlva, " H. F. Cross, ${ }^{2 !}$ and C. N. Smith. ${ }^{3 !}$ H. L. Klöpping and G.J.M. van der Kerk reported their antifungal activity. Acaricidal and herbicidal activities of benzyl ester of alkylxanthic acid were reported by N.V. Philips ${ }^{51}$ and P.C. Hamm. ${ }^{6 !}$ F. Runge ${ }^{7 /}$ reported an antifungal activity of dibenzyl trithiocarbonate. J.K.

* Present address: Chemical Laboratory, Kumiai Chemical Industry Co., Ltd., Shimizi, Shizuoka-Pref.

1) S. V. Zhuravlva, J. Applied Chem., 21, 300 (1948).

2) H.F. Cross and F.M. Snyder, Ssap Sanit. Chemicals, 25, No. 2, 135 (1949).

3) C. X. Smith and H. K. Gouch, J. Econ. Entomol., 39. $374(1946)$.

4) H. L. Klopping and G.J. M. van der Kerk, Rec. trav chim., 70, 917 (1951).

5) N.V. Philips, Belg. Patent, 628027 (1963) [C.A., 60, $15082(1964)]$.

6) P. C. Hamm and K. L. Godfrey, U.S. Patent, 2990265 (1954) [C.A., 55, 22702 (1961)].

7) F. Runge, Z. El-Hewehi, H. J. Renner and E. Taeger, I. prakt. chem., 11, 284 (1960).
Eaton $^{8 /}$ and R.F. Brooks ${ }^{9 /}$ reported acaricidal activities of diphenyl carbonate and diphenyl dithiolcarbonate, respectively. Recently, M. Pianka ${ }^{101}$ reported acaricidal activities of certain carbonates of dinitrophenols. Quinoxaline-2, 3-trithiocarbonate, 6-methylquinoxaline-2, 3-dithiolcarbonate, and sodium ethylxanthate have been sold commercially. Most of these chemicals are alkyl-, or aryl-substituted xanthates and not benzyl-substituted compounds. Although biological activities of certain carbonates are sometimes found in the literature, no systematic study of the relationship between biological activity and chemical structure of benzyl-substituted dithiocarbonates has been reported. The authors systematically synthesized various benzyl-substituted dithiocarbonates and evaluated their effectiveness as acaricides. Some dithiocarbonates showed excellent activity with eggs of Tetranychus

8) J. K. Eaton and R. G. Davies, Ann. Applied Biol. 37, $471(1950)$.

9) R. F. Brooks, J. E. Cranham, D. Greenwood and H. A. Stevenson, J. Sci. Food Agr., 8, 561 (1957).

10) M. Pianka, ibid., 17, 47 (1966). 


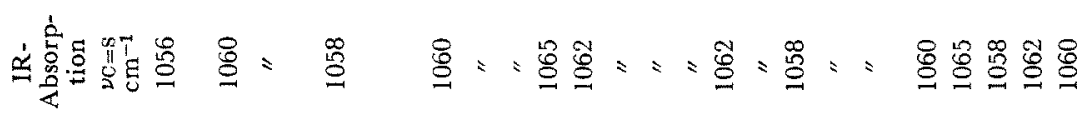

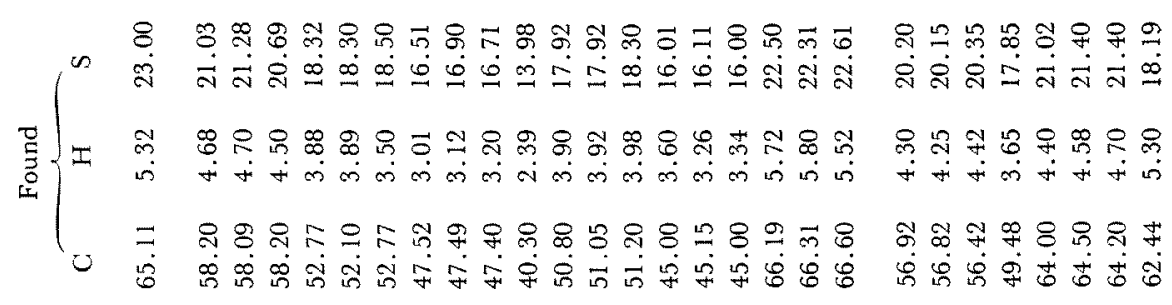

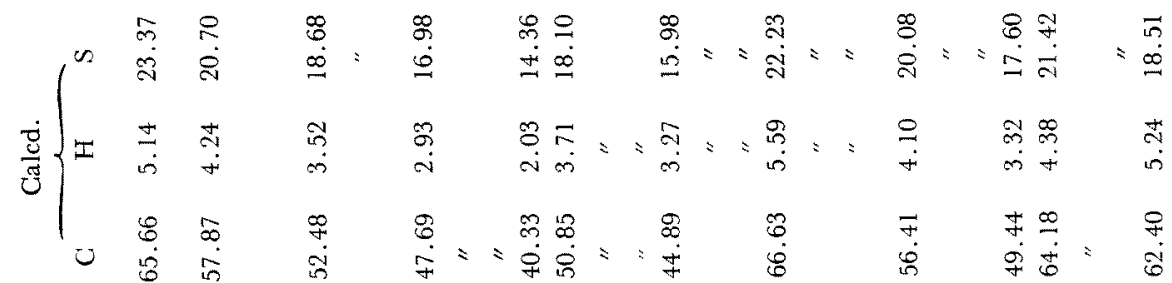

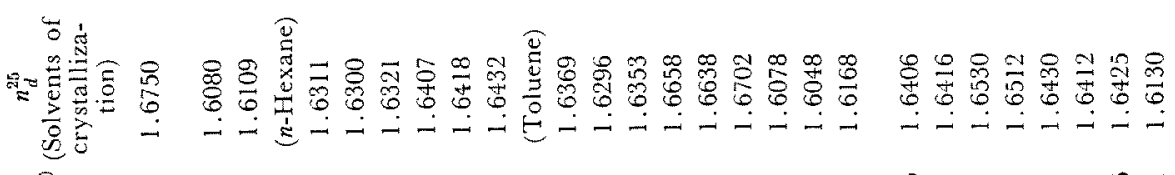

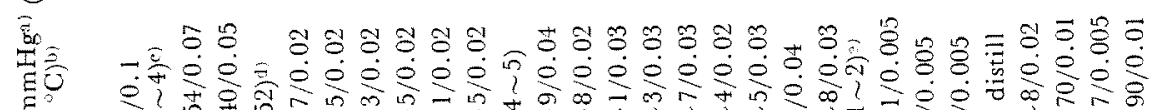

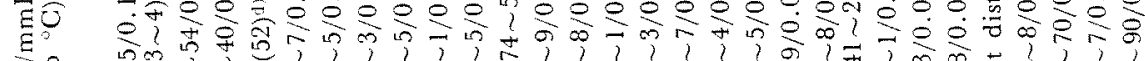

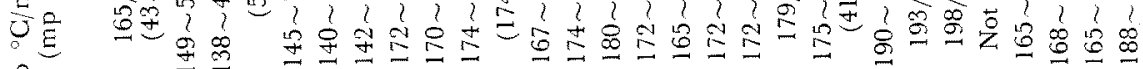
号



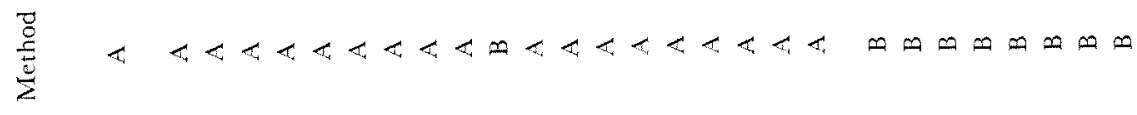

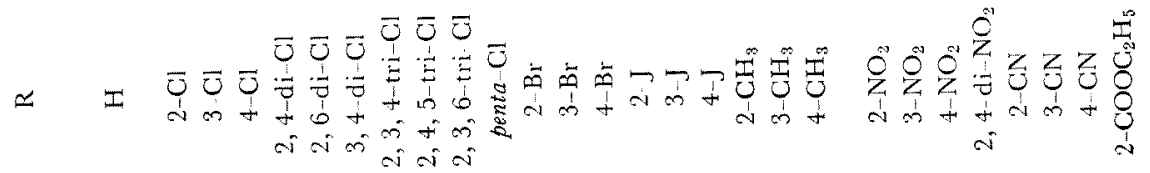




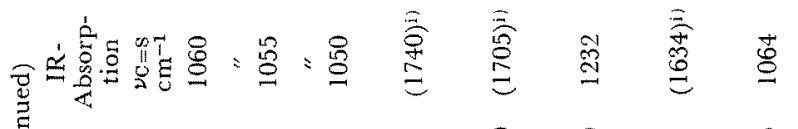

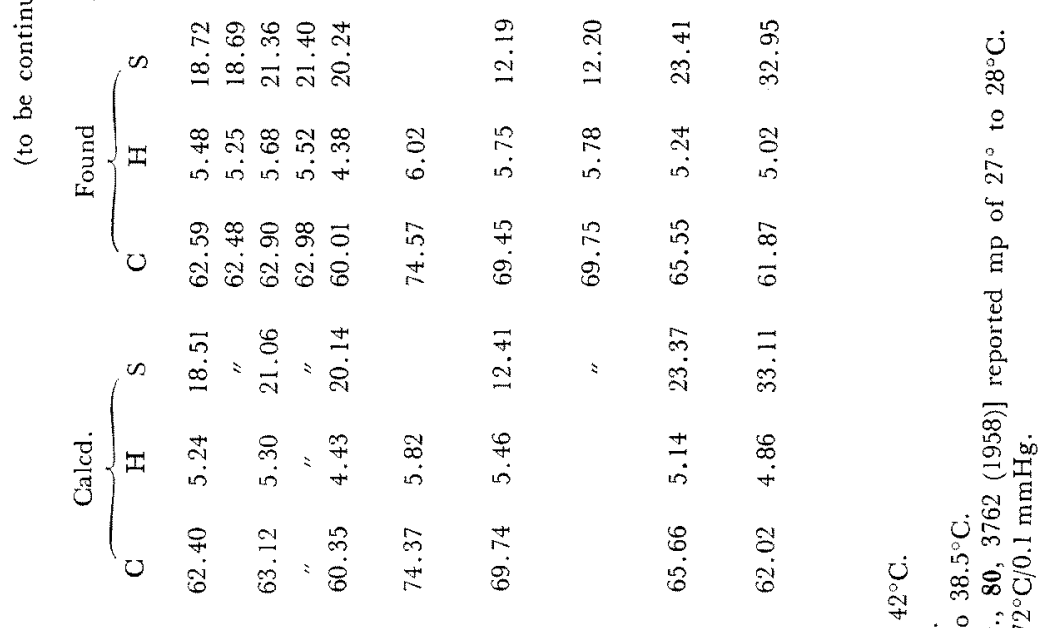

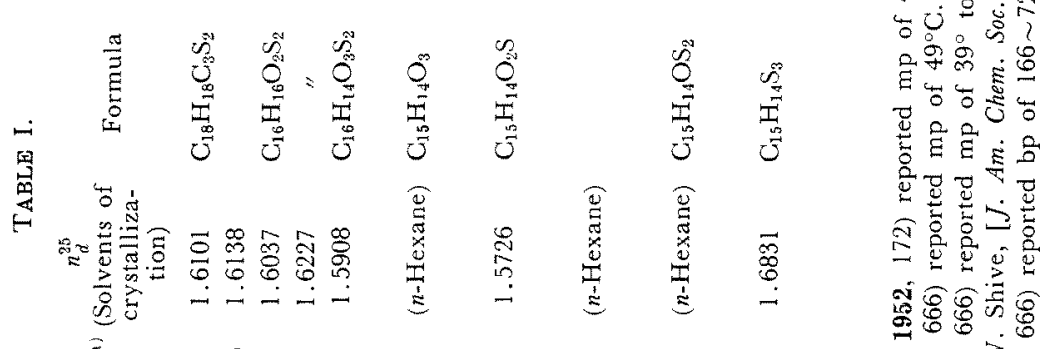

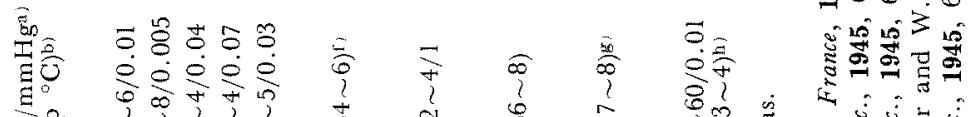

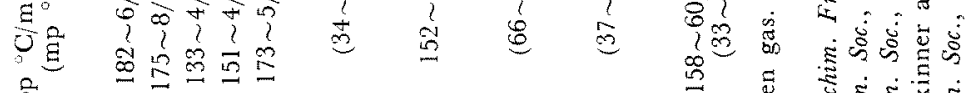

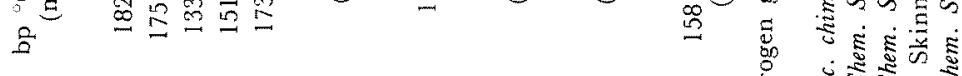

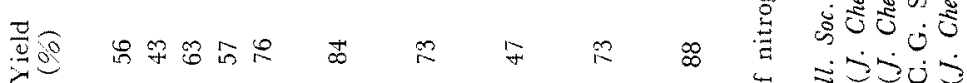

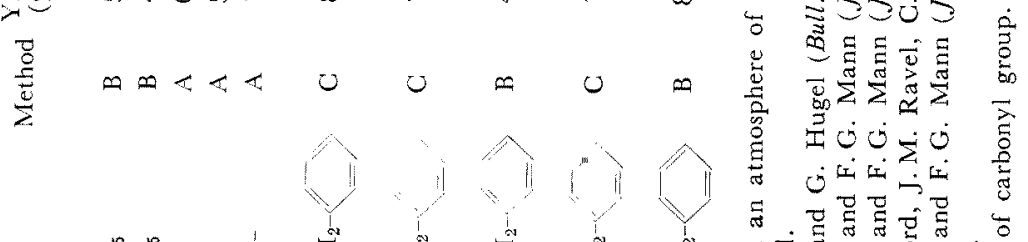

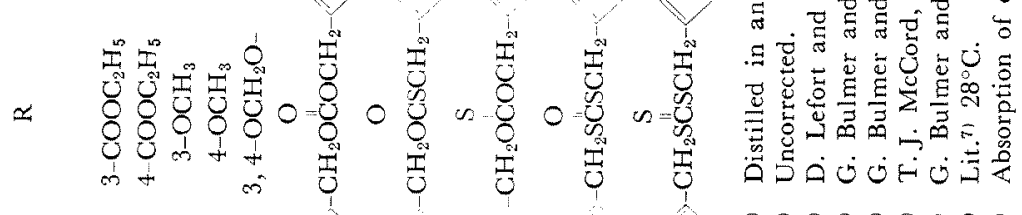


Studies on Sulfur-containing Carbonates and Their Pesticidal Activities. Part I

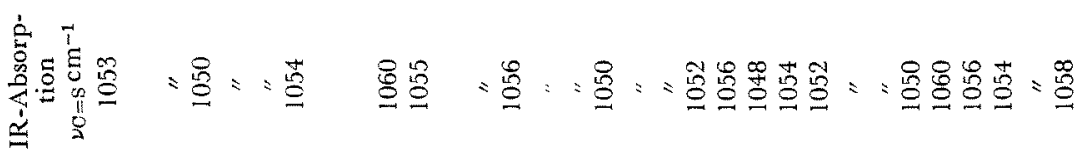

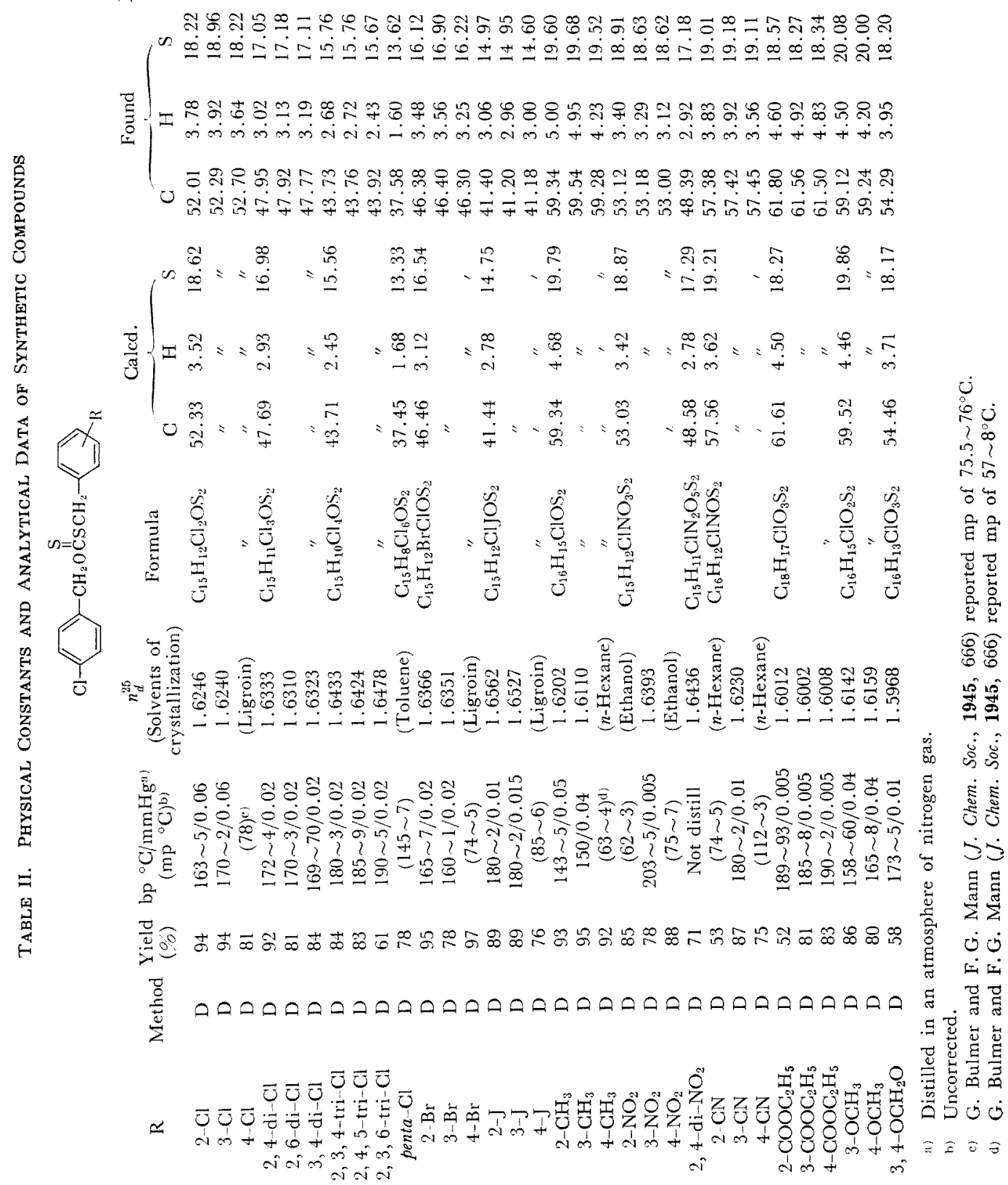


urticae Koch.

\section{MATERIALS AND METHODS}

Infrared spectrum. Infrared absorption spectra of dithiocarbonates, measured with a Hitachi EPI-G spectrophotometer, are shown in Tables I and II.

Synthesis. Most of the dithiocarbonates were synthesized from sodium O-substituted-benzyl dithiocarbonate and benzylchloride in acetone (Method A). As shown in Fig. 1, thiono-analogs $(Y=S)$ were
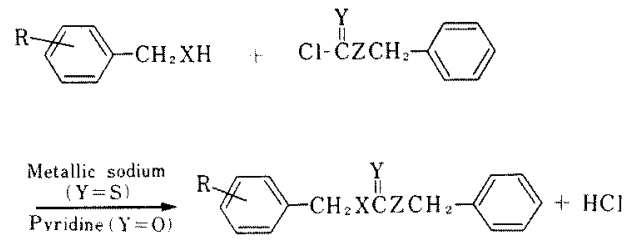

FIG. 1, Synthetic Scheme of the Carbonates.

$\mathrm{X}, \mathrm{Y}, \mathrm{Z}$ : Oxygen or sulfur atoms, $\mathrm{R}$ : hydrogen atom, cyano-, nitro-, ethoxycarbonyl- and pentachloro-groups.

synthesized by the action of metallic sodium in a heated condition (Method $\mathrm{B})$, and oxo-analogs $(\mathrm{Y}=\mathrm{O}$ ) were synthesized by the action of pyridine in a cooled condition (Method C). Moreover, S-substituted-benzyl O-4-chlorobenzyl dithiocarbonates were synthesized from sodium O-4-chlorobenzyl dithiocarbonate and substituted benzylbromide in acetone (Method D). Liquid compounds were distilled in an atmosphere of nitrogen gas under a vacuum. Physical constants and analytical data for compounds prepared are given in Tables I and II. Most of them are new compounds, and details of some typical preparations are described below.

Method A. S-Benzyl O-2-chlorobenzyl dithiocarbonate. Into a mixture of $8.1 \mathrm{~g}$ of sodium O-2-chlorobenzyl dithiocarbonate and $100 \mathrm{ml}$ of acetone, $3.8 \mathrm{~g}$ of benzylchloride was added dropwise at $30 \sim 35^{\circ} \mathrm{C}$. After this addition, the reaction mixture was stirred at $30 \sim 35^{\circ} \mathrm{C}$ for an additional $2 \mathrm{hr}$, then the acetone was removed. The residue was extracted with $100 \mathrm{ml}$ of ether, and washed with several portions of water. Ether was removed after drying over anhydrous sodium sulfate. The residue was distilled at $149 \sim 154^{\circ} \mathrm{C}(0.07 \mathrm{mmHg})$ in an atmosphere of nitrogen gas to yield $4.4 \mathrm{~g}$ of oil.
Method B. S-Benzyl O-4-cyanobenzyl dithiocarbonate. A mixture of $0.5 \mathrm{~g}$ of metallic sodium and $5.4 \mathrm{~g}$ of 4-cyanobenzylalcohol in $100 \mathrm{ml}$ of dried toluene was heated to give the alcoholate, then $4 \mathrm{~g}$ of S-benzyl dithiochloroformate $\left(\mathrm{Bp}=107 \sim 113^{\circ} \mathrm{C} \quad(0.25 \mathrm{mmHg})\right)$ was dropwise added into the alcoholate suspension at $90 \sim 100^{\circ} \mathrm{C}$. After the addition of the dithiochloroformate, the reaction mixture was refluxed for $8 \mathrm{hr}$ and filtrated. The filtrate was washed with several portions of water and dried over anhydrous sodium sulfate. The solvent was removed in vacuo and the residue was distilled at $165 \sim 167^{\circ} \mathrm{C}(0.005 \mathrm{mmHg})$ in an atmosphere of nitrogen gas to yield $4.7 \mathrm{~g}$ of oil.

Method C. S-Benzyl O-benzyl thiolcarbonate. Into a mixture of $9.3 \mathrm{~g}$ of S-benzyl thiolchloroformate and $5.4 \mathrm{~g}$ of benzylalcohol in $100 \mathrm{ml}$ of toluene, $4.2 \mathrm{~g}$ of pyridine was added dropwise with stirring and cooling in an ice bath. After this addition, the reaction mixture was stirred at room temperature for an additional $2 \mathrm{hr}$, then sequentially washed with water, dilute hydrochloric acid and several portions of water. The solvent was removed in vacuo after drying over anhydrous sodium sulfate. The residue was distilled at $152 \sim 154^{\circ} \mathrm{C}(1 \mathrm{mmHg})$ to yield $9.4 \mathrm{~g}$ of oil.

Method D. S-4-Bromobenzyl O-4-chlorobenzyl dithiocarbonate. Into a mixture of $8.1 \mathrm{~g}$ of sodium O-4-chlorobenzyl dithiocarbonate and $100 \mathrm{ml}$ of acetone, $7.5 \mathrm{~g}$ of 4-bromobenzylbromide was added dropwise at $40 \sim$ $45^{\circ} \mathrm{C}$. After completion of the addition, the mixture was stirred at $40 \sim 45^{\circ} \mathrm{C}$ for an additional $4 \mathrm{hr}$, then the acetone was removed. The residue was extracted with $100 \mathrm{ml}$ of ether and washed with water. Ether was removed after drying over anhydrous sodium sulfate. The residue was recrystallized from ligroin to yield $11.2 \mathrm{~g}$ of pale yellow needles, $\mathrm{mp}=74 \sim 75^{\circ} \mathrm{C}$.

\section{Acaricidal activity}

Mortality of eggs. The leaf of a potted kidney bean plant was cut into a disc (diameter $3 \mathrm{~cm}$ ), then placed for the oviposition of five females of Tetranychus urticae Koch for 1 day. After counting the deposited eggs, the leaves were dipped in a testing solution of prescribed concentration for 10 seconds, then kept at $30^{\circ} \mathrm{C}$.

A mortality count was made under a binocular microscope when the untreated eggs hatched. Egg mortality was corrected by Abbott's formula11 with

11) N.S. Abbott, $J$. Econ. Entomol, 18, 265 (1925). 
the mortality of control samples. The median lethal concentration was estimated on the graph of a $\log$ dose-probit line. ${ }^{12 \sim 15}$

Mortality of adults. The leaf of a potted kidney bean plant was dipped for 10 seconds in the testing solution. After drying about 50 adults of Tetranychus urticae Koch were transferred to the treated leaf, which was kept for $48 \mathrm{hr}$ at $30^{\circ} \mathrm{C}$. The median lethal concentration was determined as described in the preceeding paragraph.

\section{RESULTS AND DISCUSSION}

Acaricidal activities of the dithiocarbonates are shown in Tables III and IV. Generally speaking, these dithiocarbonates were effective with eggs, but showed scarcely any activity with adults. Almost all commercial acaricides

TABLE III. ACARICIDAL ACTIVITIES OF S-BENZYL O-SUBSTITUTED-BENZYL DithIOCARBonates ON Tetranychus urticae Koch.a)

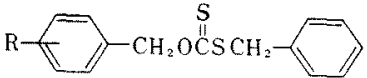

Acaricidal

$\mathrm{R}$

\section{2- $\mathrm{Cl}$}

2, 4-di-Cl

$2,6-\mathrm{di}-\mathrm{Cl}$

$2,3,4$-tri-Cl

2, 4, 5-tri-Cl

$2,3,6$-tri-Cl

penta-Cl

$2-\mathrm{Br}$

2-J

$2-\mathrm{CH}_{3}$

$2-\mathrm{NO}_{2}$

$2,4-\mathrm{di}-\mathrm{NO}_{2}$

$2-\mathrm{CN}$

$2-\mathrm{COOC}_{2} \mathrm{H}_{5}$ 4- $\mathrm{OCH}_{3}$

$4-\mathrm{CH}_{3}$

$3,4-\mathrm{OCH}_{2} \mathrm{O}-$

$3-\mathrm{CH}_{3}$

$\mathrm{H}$

$3-\mathrm{OCH}_{3}$

4-CI

4-Br

$4-\mathrm{J}$

$3-\mathrm{J}$

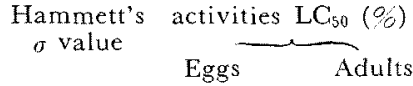

Eggs Adults

$$
9.21 \times 10^{-3} \quad 10^{-1}<
$$

$1.90 \times 10^{-2}$

1. $70 \times 10^{-2}$

$2.44 \times 10^{-2}$

$4.53 \times 10^{-2}$

$4.51 \times 10^{-2}$

$10^{-2}$

$1.53 \times 10^{-2}$

$10^{-2}$

$6.00 \times 10^{-3}$

$1.40 \times 10^{-2}$

$8.59 \times 10^{-2}$

$5.28 \times 10^{-2}$

$5.01 \times 10^{-2}$

$-0.268 \quad 5.81 \times 10^{-3}$

$-0.170 \quad 9.71 \times 10^{-4}$

$-0.159 \quad 1.06 \times 10^{-3}$

$-0.0697 .32 \times 10^{-4}$

$0.000 \quad 6.60 \times 10^{-4}$

$0.1153 .30 \times 10^{-4}$

$0.227 \quad 2.20 \times 10^{-4}$

$0.232 \quad 2.85 \times 10^{-4}$

$0.276 \quad 3.42 \times 10^{-4}$

$0.3525 .10 \times 10^{-4}$
"

$3-\mathrm{Cl}$

$3-\mathrm{Br}$

$3-\mathrm{COOC}_{2} \mathrm{H}_{5}$

$4-\mathrm{COOC}_{2} \mathrm{H}_{5}$

3, 4-di-Cl

4-CN

$3-\mathrm{CN}$

3- $\mathrm{NO}_{2}$

4- $\mathrm{NO}_{2}$
Acaricidal

Hammett's activities $\mathrm{LC}_{50}(\%)$
$\sigma$ value

$\mathrm{R}$

$0.373 \quad 5.51 \times 10^{-4} \quad 10^{-1}<$

$0.3915 .80 \times 10^{-4} \quad$ "

$0.3985 .81 \times 10^{-4} \quad$ "

$0.5229 .01 \times 10^{-4} \quad$ "

$0.600^{\text {b }} 2.62 \times 10^{-3}$

$0.628 \quad 4.22 \times 10^{-3} \quad$ "

$0.678 \quad 5.43 \times 10^{-3} \quad$ "

$0.710 \quad 5.62 \times 10^{-3} \quad$ "

$0.7787 .31 \times 10^{-3} \quad$ "I

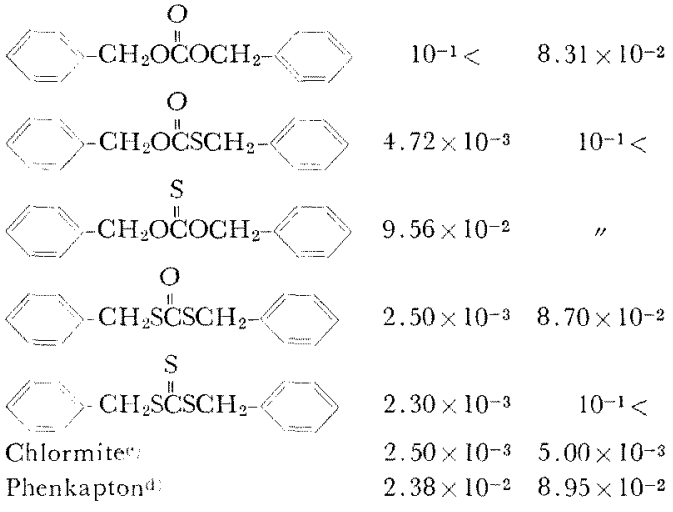

a) Normal susceptible strain.

b) Sum of Hammett's $\sigma$ values.

c) Isopropyl 4, 4'-dichlorobenzilate.

d) O,O-Diethyl S-(2,5-dichlorophenylmercaptomethyl) dithiophosphate.

12) C. I. Bliss, Science, 79, 38 (1934); idem., ibid., idem., ibid., 22, 307 (1935). 79, 409 (1934).

i3) C.I. Bliss, Ann. Applied Biol., 22, 134 (1935)

14) C. I. Bliss, J. Econ. Entomol., 29, 143 (1936).

$15)$ C. I. Bliss, Ann. Applied Biol., 24, 815 (1937). 
which show high activity on adults have hydrophilic groups in their chemical structure. Some acaricides which are effective with eggs have lipophilic groups. The dithiocarbonates, represented by the general structure $-\mathrm{O}-\mathrm{C}(=\mathrm{S})-$ $\mathrm{SCH}_{2}-\mathrm{C}_{6} \mathrm{H}_{5}$, have no hydrophilic group. On the contrary, these compounds are considered to be lipophilic. Therefore, these dithiocarbonates are highly effective on eggs but are not so effective on adults. Consequently, in order to increase the hydrophilicity of the dithiocarbonates, a nitro group was introduced into the benzene ring of the dithiocarbonates. The nitro-substituted dithiocarbonates, however, showed scarcely any activity with adults. As shown in Table III, compounds having $-\mathrm{SCH}_{2}-$ $\mathrm{C}_{6} \mathrm{H}_{5}$ structure in the compounds represented with the general structure $\mathrm{C}_{6} \mathrm{H}_{5}-\mathrm{CH}_{2}-\mathrm{X}$ $\mathrm{C}(=\mathrm{Y})-\mathrm{Z}-\mathrm{CH}_{2}-\mathrm{C}_{6} \mathrm{H}_{5}(\mathrm{X}, \mathrm{Y}, \mathrm{Z}$ : oxygen and sulfur atoms) showed high activity with eggs. Compounds without this structure were ineffective with eggs. S-Benzyl O-benzyl dithiocarbonate showed a specially excellent ovicidal activity. On the other hand, the authors introduced various substituents into the aromatic ring of O-benzyl of S-benzyl O-benzyl dithiocarbonate. Generally, ovicidal activity was increased by the introduction of various substituents into the meta- or para-positions of the benzene ring of O-benzyl of S-benzyl O-benzyl dithiocarbonate, but it was decreased by the introduction of substituents into the ortho-position. For example, some S-benzyl O-3- or 4-substitutedbenzyl dithiocarbonates, such as halogeno-, methoxy-, methyl- and ethoxycarbonyl-substituted compounds, were highly effective on eggs. S-Benzyl O-4-chloro-benzyl dithiocarbonate, S-benzyl O-4-bromo-benzyl dithiocarbonate, and S-benzyl O-3-methoxybenzyl dithiocarbonate showed especially excellent ovicidal activity. The ovicidal activity, however, was remarkably diminished by the introduction of poly-chloro-, nitro- and cyano-groups into the benzene ring of O-benzyl of S-benzyl O-substituted-benzyl dithiocarbonate. Some S-benzyl O-2-substituted-benzyl dithiocarbonates, such as halogeno-, methyl- and ethoxycarbonylsubstituted compounds, showed no activity. As mentioned above, the order of increasing of activity caused by the introduction of halogen atom into benzene ring of O-benzyl was $\mathrm{Cl}>\mathrm{Br}>\mathrm{I}>$ di- $\mathrm{Cl}>$ tri- $\mathrm{Cl}>$ penta-Cl. There

TABLE IV. ACARICIDAL ACTIVITIES OF S-SUBSTITUTED-BENZYL O-4-ChLOROBENZYL DITHIOCARBONATES ON Tetranychus urticae KOCH."
$2-\mathrm{Cl}$

$2,4-\mathrm{di}-\mathrm{Cl}$

$2,6-\mathrm{di}-\mathrm{Cl}$

$2,3,4-$ tri-Cl

2, 4, 5-tri-Cl

2, 3, 6-tri-Cl

penta- $\mathrm{Cl}$

2-Br

2-J

$2-\mathrm{CH}_{3}$

$2-\mathrm{NO}_{2}$

2, 4-di- $\mathrm{NO}_{2}$

$2-\mathrm{CN}$

2- $\mathrm{COOC}_{2} \mathrm{H}_{5}$

${ }_{4}-\mathrm{OCH}_{3}$

$4-\mathrm{CH}_{3}$

$3,4-\mathrm{OCH}_{2} \mathrm{O}-$

$3-\mathrm{CH}_{3}$

$3-\mathrm{OCH}_{3}$

4- $\mathrm{Cl}$

$4-\mathrm{Br}$

4-J

$3-\mathrm{J}$

3- $\mathrm{Cl}$

$3-\mathrm{Br}$

3- $\mathrm{COOC}_{2} \mathrm{H}_{5}$

4- $\mathrm{COOC}_{2} \mathrm{H}_{5}$

3, 4-di-Cl

4- $\mathrm{CN}$

3-CN

$3-\mathrm{NO}_{2}$

$4-\mathrm{NO}_{2}$

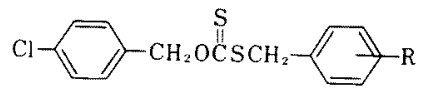

Acaricidal

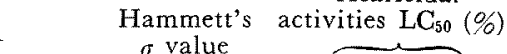
$\sigma$ value $\overbrace{\text { Eggs }}^{\text {Adult }}$ $8.60 \times 10^{-3} \quad 10^{-1}<$ $1.80 \times 10^{-2}$ $1.62 \times 10^{-2} \quad$ "I $3.91 \times 10^{-2}$ $3.42 \times 10^{-2}$ $3.48 \times 10^{-2}$ $10^{-2}<$

$1.20 \times 10^{-2}$

$4.19 \times 10^{-2}$

$5.01 \times 10^{-3}$ $10^{-2}<$

" $10^{-1}<$

$3.11 \times 10^{-2}$

$3.01 \times 10^{-3}$

$7.44 \times 10^{-4}$

$1.92 \times 10^{-3}$

$3.20 \times 10^{-4} \quad 9.52 \times 10^{-2}$

$4.00 \times 10^{-4} \quad 10^{-1}<$

$6.80 \times 10^{-4}$

$7.53 \times 10^{-4}$

$8.22 \times 10^{-4}$

$1.00 \times 10^{-3}$

$2.12 \times 10^{-3}$

$2.04 \times 10^{-3}$

$2.43 \times 10^{-3}$

$6.30 \times 10^{-3}$

$9.51 \times 10^{-3}$

$1.10 \times 10^{-2}$

$2.21 \times 10^{-2}$

$5.86 \times 10^{-2}$

$8.62 \times 10^{-2}$ a) Normal susceptible strain.

b) Sum of Hammett's $\sigma$ values. 
is a definite relationship between the position of substituents on the benzene ring and ovicidal activity. That is, the order of increasing ovicidal activity caused by the introduction of a halogen atom and a cyano group was para->meta->ortho-position, but the order of activity caused by methyl-, methoxy-, nitroand ethoxycarbonyl-groups was meta $>$ para $>$ ortho. The remarkable decreasing of ovicidal activity broughts about by the introduction of substituents into the ortho-position suggests that the steric hindrance to active site in mite may be increased by the substituent of the orthoposition. On the other hand, as shown in Table IV, ovicidal activity was decreased by the introduction of various substituents into the benzene ring of the S-benzyl group of Sbenzyl O-4-chlorobenzyl dithiocarbonate. That is, a remarkable decrease of ovicidal activity was caused by the introduction of nitro-, cyano- and methylenedioxy-groups into the benzene ring. Moreover, a greater number of substituents showed much lower activities. For example, the activities of polychlorinated- and dinitro-compounds were lower than those of mono-chloro- and mononitro-compounds, respectively. But the introduction of methyl- and methoxy-groups into the meta-position of the benzene ring showed the same levels of activity as for non-substituted compounds. That is, some S-substituted-benzyl O-4-chlorobenzyl dithiocarbonates, such as S-4-halogeno-substituted, S-3-, or 4-methyl-substituted, and S-3-methoxysubstituted, were highly effective with eggs. S-3-Methylbenzyl O-4-chlorobenzyl dithiocarbonate and S-3-methoxybenzyl O-4-chlorobenzyl dithiocarbonate showed especially excellent ovicidal activity.

The introduction of a halogen atom into the benzene ring of S-benzyl showed the same tendency as obtained with O-benzyl. The order of increasing ovicidal activity of Shalogenobenzyl O-4-chlorobenzyl dithiocarbonates was $\mathrm{Cl}>\mathrm{Br}>\mathrm{I}>$ di- $\mathrm{Cl}>$ tri- $\mathrm{Cl}>$ penta- $\mathrm{Cl}$. The position of substituents in the benzene ring showed a definite relationship with ovicidal activity. The same tendency as mentioned above was also recognized in S-substitutedbenzyl O-4-chlorobenzyl dithiocarbonates. In them the order of increasing ovicidal activity caused by the introduction of a halogen atom and a cyano group into the benzene ring of the S-benzyl of S-substituted-benzyl O-4-chlorobenzyl dithiocarbonate was para-> meta->orthopositions, but the order of increasing activity caused by methoxy-, methyl-, nitro- and ethoxycarbonyl-groups was meta>para>ortho. Thus, dithiocarbonates having halogen, methyl, methoxy and ethoxycarbonyl groups at the meta- and para-positions of benzyl group were more active with eggs than were Chlormite and Phenkapton, but these were far less active with adults than Chlormite and Phenkapton. The effectiveness with adults of O, O-dibenzyl carbonate, S, S-dibenzyl dithiolcarbonate, and S-3-methylbenzyl O-4-chlorobenzyl dithiocarbonate was similar to that of Phenkapton. Recently, in order to explain the correlation of biological activity and chemical structure, Hammett's $\sigma$ constant, the oil-water partition coefficient and $\mathrm{pKa}$-value were applied by several investigators. ${ }^{16201}$ In order to discuss the relationship between the electronic property of the molecule and its acaricidal activity, the authors applied Hammett's $\sigma$ constant $^{18,21,221}$ to these dithiocarbonates. As shown in Tables III and IV, however, there is no parallel relationship between ovicidal activity and Hammett' $\sigma$ constant, although ovicidal activity was decreased by the introduction of substituents having nega-

16) T. R. Fukuto and R. F. Metcalf, J. Agr. Food Chem., 4, 930 (1956).

17) C. Hansch, R. M. Muir, T. Fujita, P.P. Maloney, F. Geiger and M. Streich, J. Am. Chem. Soc., 85, 2817 (1963).

18) C. Hansch and T. Fujita, ibid., 86, 1616 (1964).

19) T. Fujita, J. Iwasa and C. Hansch, ibid., 86, 5175 (1964)

20) T. Fujita, J. Medicinal Chem., 9, 797 (1966).

21) R.W. Taft, Jr., in M.S. Newman, "Steric Effects in Organic Chemistry," Wiley, New York, 1956 , p. 571.

22) H. H. Jaffe, Chem. Rev., 53, 191 (1953). 
tive or large positve $\sigma$ values.

Aknowledgements. The authors express their sincere thanks to Dr. K. Munakata, Professor of Nagoya

University, for his kindly advice. The authors also wish to express their hearty thanks to Miss M. Ohsone of the Research Laboratory, Tōa Agricultural Chemical Co., Ltd., for the elemental analyses and measurement of infrared absorption spectra. 